\title{
O diálogo entre esportes e o juiz supranacional: o reenvio prejudicial
}

\author{
The dialogue between sports and the supranational judge: the preliminary ruling
}

\author{
Cláudio Finkelstein*
}

Rita de Cassia Carvalho Lopes ${ }^{* *}$

\author{
REFERÊNCIA \\ FINKELSTEIN, Cláudio. LOPES, Rita de Cassia Carvalho. O DIÁLOGO ENTRE ESPORTES E O JUIZ \\ SUPRANACIONAL: O Reenvio Prejudicial. Revista da Faculdade de Direito da UFRGS, Porto Alegre, n. 47 , \\ p. 110-132, dez. 2021. DOI: https://doi.org/10.22456/0104-6594.113592.
}

\section{RESUMO}

O presente artigo objetiva analisar o diálogo entre o sistema nacional e o sistema supranacional da ordem comunitária europeia, sob a perspectiva do reenvio a título prejudicial, cujo desenvolvimento impacta no subsistema do direito desportivo. $\mathrm{O}$ trabalho, também, trata dos reflexos dos diálogos entre essas ordens jurídicas que têm potencial para restringir a autonomia da lex sportiva. Para tanto, cita-se decisão do Tribunal de Justiça da União Europeia que discute o conceito de esporte, num contexto sobre isenção tributária. O artigo ocupa-se das facetas desse diálogo, partindo da importância da jurisprudência do Tribunal de Justiça da União Europeia e concluindo que são possíveis outras interações entre esses sistemas jurídicos, especialmente quanto a direitos fundamentais. O artigo utiliza o método dedutivo, que parte dos conceitos para aplicação na hipótese.

\section{PALAVRAS-CHAVE}

Direito Desportivo. Direito Comunitário Europeu. Reenvio Prejudicial. Interação entre Sistemas Jurídicos.

\begin{abstract}
This paper aims to analyse the dialogue between the national system and the supranational system in the European Union legal order, particularly under the perspective of the preliminary ruling, since its development affects the sports law subsystem. The work also deals with the reflection of the dialogues between these legal systems that have potential to restrict the autonomy of the lex sportiva. For this purpose, it quotes the ruling from the European Court of Justice that considers the concept of sports, in a tax exemption context. The research is about the aspects of that dialogue, starting from the importance of the jurisprudence of the European Court of Justice and concluding that other interactions between these legal systems are possible, particularly regarding fundamental rights. The paper adopts a deductive method from the concepts to apply them on the hypothesis.
\end{abstract}

\section{KEYWORDS}

Sports Law. European Law. Preliminary Ruling. Interaction between Legal Systems.

\section{SUMÁRIO}

1.Introdução. 2. A construção do sistema europeu e o direito comunitário na perspectiva dos esportes. 3. O Tribunal de Justiça da União Europeia e o reenvio prejudicial. 4. Exemplo de impacto da uniformização do direito comunitário no esporte. 5. Os diálogos entre juízes e o esporte na União Europeia. 6.Conclusão. Referências. Dados da publicação.

\footnotetext{
* Livre Docente pela Pontifícia Universidade Católica de São Paulo (PUC-SP), Doutor em Direito pela Pontifícia Universidade Católica de São Paulo (PUC-SP), Mestre em Direito em Direito Internacional pela University of Miami; Professor da Pontifícia Universidade Católica de São Paulo (PUC-SP) e Coordenador da área de Arbitragem e Comércio Internacional no Pós-Graduação das PUCSP.

** Doutoranda em Direito das Relações Econômicas Internacionais pela Pontifícia Universidade Católica de São Paulo (PUC-SP), Mestre em Ciências Jurídico-Internacionais pela Faculdade de Direito da Universidade de Lisboa e Advogada.
} 


\section{INTRODUÇÃO}

A regulamentação do esporte, originariamente, é feita por entidades desportivas, eminentemente privadas, em vários níveis, com configurações particulares que transcendem fronteiras. Essa regulamentação corporativa específica é a lex sportiva, que, atualmente, convive com o direito estatal.

Quanto ao subsistema do direito desportivo, verifica-se que recebe influência dos sistemas maiores em que está inserido e sofre impactos particulares dessas ordens. Esse reflexo ocorre de forma especial no continente europeu, em que o direito desportivo, além de conviver com o sistema jurídico dos Estados-Membros, está sob a égide de um direito comunitário.

Este trabalho trata da interação entre sistemas jurídicos e, especialmente, do reenvio a título prejudicial ${ }^{1}$, no contexto do direito comunitário, que é procedimento de cooperação com a função de efetivar um diálogo entre o juiz nacional e o juiz supranacional, no que diz respeito à interpretação e à validade do direito comunitário junto ao Tribunal de Justiça da União Europeia (TJUE), cujo resultado é uma decisão com efeito vinculante.

Ressalte-se que, apenas em 2009, a União Europeia (UE) incluiu o esporte nos temas de seus tratados, sem, contudo, estabelecer uma política comunitária comum. Neste cenário, o TJUE tem feito contribuições pontuais, para interligar os sistemas nacional e supranacional, no que tange à temática esportiva.

No intuito de dar unidade ao direito comunitário europeu, o TJUE interpreta, valida e cria normas, expandindo, a influência do direito comunitário sobre todos os subsistemas de direito dos Estados-Membros da UE, sendo certo que a atividade do TJUE é especial, em relação ao subsistema esportivo, já que esse não está sistematizado, no bloco europeu como política comum e, ainda, convive com uma atividade de regulamentação corporativa bastante forte das associações desportivas.

Desta forma, por meio do procedimento do reenvio prejudicial, a atividade pretoriana torna-se instrumento de interação entre ordens e impacta no desenvolvimento da

\footnotetext{
${ }^{1}$ Este mecanismo foi instituído pelos tratados fundadores artigos $177^{\circ}$ do TCEE e $41^{\circ}$ do CECA. "Por influência da doutrina estrangeira têm-se generalizado em português expressões como 'reenvio prejudicial', fazendo uma tradução literal da expressão renvoi préjudiciel. [...] reenvio é instituto de Direito Internacional Privado, que signifíca devolução [...].” Cf. QUADROS, Fausto de; MARTINS, Ana Maria Guerra. Contencioso Comunitário. Coimbra: Almedina. 2005, p. 46. Reenvio, no Direito Internacional Privado, é o conflito negativo de elementos de conexão. Prejudiciais são questões (de direito material ou processual) que influenciam a resolução do mérito. Trata-se por prejudicial não qualquer questão prévia, mas apenas aquela que se caracterizar como um antecedente lógico e necessário à solução do mérito.
} 
regulamentação corporativa e do subsistema esportivo, particularmente através da cooperação entre juiz nacional e supranacional.

Verifica-se, portanto, que a interação entre os sistemas tem potencial para afetar a autonomia do fenômeno desportivo, através de restrições advindas da ordem supranacional, seja porque as decisões têm efeito territorial alargado, seja porque elas atingem muitos sujeitos, o que diminui a capacidade de reação das entidades esportivas não estatais e das unidades políticas estatais, reequilibrando as relações esportivas. Tais restrições têm potencial para serem, ainda, mais profundas, quando se referirem aos direitos fundamentais.

\section{A CONSTRUÇÃO DO SISTEMA EUROPEU E O DIREITO COMUNITÁRIO NA PERSPECTIVA DOS ESPORTES}

No pós-segunda guerra mundial, pensou-se em concentrar e controlar a produção de matéria-prima, que poderia servir para futuros fins bélicos e, ao mesmo tempo, estimular a indústria, gerar empregos e aquecer a economia. Nesta linha, ao redor do carvão e do aço, e sob uma autoridade comum, inicia-se o movimento de integração europeu como se conhece hoje.

Criou-se a Comunidade Europeia do Carvão e do Aço (CECA), cuja autoridade comum era um órgão com personalidade independente, com poderes efetivos de regulação do mercado e em articulação com os governos nacionais dos Estados envolvidos.

Paulatinamente, foi formada uma arquitetura complexa, em que foram feitas transferências graduais dos poderes dos Estados-Membros em relação a diferentes setores da vida econômica ${ }^{2}$ e foram instituídos órgãos para sustentar essa estrutura, como o TJUE ${ }^{3}$.

A integração econômica europeia foi feita em fases ${ }^{4}$, com a concepção de um espaço no qual são asseguradas a livre circulação de mercadorias, pessoas, serviços e capitais ${ }^{5}$ e, a fim de garantir a implementação desses quatro fatores de produção, os Estados-Membros estavam impedidos de criar obstáculos a essas "quatro liberdades" e à livre concorrência 7 .

\footnotetext{
${ }^{2}$ CUNHA, Paulo Pitta. Direito Institucional da União Europeia. Coimbra: Almedina, 2004, p. 17.

${ }^{3}$ Em 1957, era designado por Tribunal de Justiça das Comunidades Europeias (TJCE) e, a partir do Tratado de Lisboa (2009), passou a denominar-se Tribunal de Justiça da União Europeia (TJUE).

${ }^{4}$ As fases de integração econômica são: zona de livre comércio, união aduaneira, mercado comum e união econômica e monetária. ACCIOLY, Elizabeth. Mercosur \& Unión Europea: estrutura jurídico-institucional. 2. ed. Curitiba: Juruá, 1998, p. 27-54. Desde 1995, o bloco está em marcha com o projeto de integração política e não apenas econômica.

${ }^{5}$ Artigo $26^{\circ}$, itens 1 e 2, do Tratado de Funcionamento da União Europeia (TFUE). O TFUE é a revisão do Tratado da Comunidade Europeia (TCE), que por sua vez, advém do Tratado da Comunidade Econômica Europeia (TCEE).

${ }^{6}$ Conferir a livre circulação de mercadorias (arts. $28^{\circ}$ a $37^{\circ}$ do TFUE), livre circulação de pessoas, serviços e capitais (arts. $45^{\circ}$ a $66^{\circ}$ do TFUE).

${ }^{7}$ Artigos $101^{\circ}$ e $102^{\circ}$ do TFUE.
} 
Aquela normatização econômica reverberou na temática esportiva porque esse fenômeno não havia sido disciplinado pelos tratados originários da UE e o processo de integração europeu seguiu avançando, independentemente de vácuos legislativos.

Em alguma medida, isso foi possível, em primeiro lugar, devido ao fato de que a UE comporta um sistema sui generis, em que permanecem elementos de cooperação intergovernamental e em segundo lugar devido ao fato de que a competência legislativa comunitária não é geral, mas limitada a áreas em que ocorre transferência de poderes por parte dos Estados-Membros ${ }^{8}$. Assim, ambas as razões deixam espaço para a determinação política autônoma dos Estados-Membros em algumas temáticas, ao mesmo tempo em que esse ambiente vai sendo restringido, voluntariamente, no exercício da própria soberania estatal, na medida em que a competência da UE passa a tratar de novas matérias.

No processo de integração, o sistema avançou para a construção de um direito comunitário 9 para regular as relações multilaterais entre os seus Estados-Membros, referente àquele processo. Contudo, o sistema comunitário, ainda, constitui uma ordem jurídica nova e complexa, na qual se detectam lacunas e insuficiências no tratamento de questões, que não foram previstas e muito menos reguladas exaustivamente, a exemplo do direito desportivo.

Apesar das lacunas, o sistema comunitário em construção ${ }^{10}$ deve se relacionar de forma coerente com os sistemas jurídicos supranacional e nacional. Para que essa unidade entre sistemas fosse efetuada, fez-se necessário que o TJUE produzisse jurisprudência com essa finalidade.

No caso do fenômeno esportivo, o TJUE, na sua atividade pretoriana, teve que lidar com a ausência de previsão nos tratados originários sobre a temática e socorreu-se da vertente econômica de integração europeia para julgar casos relativos ao esporte, em termos comunitários, nos momentos em que foi chamado a se manifestar ${ }^{11}$. Assim, o órgão judicante

\footnotetext{
${ }^{8}$ CUNHA, Paulo Pitta. Direito Institucional da União Europeia. Coimbra: Almedina, 2004, p. 34 e 39.

${ }^{9} \mathrm{O}$ direito comunitário é um direito relativo ao processo de integração, que regula as relações multilaterais dos Estados-Membros. Ele é formado por normas de tratados internacionais (direito comunitário originário) e por atos normativos emanados das instituições comunitárias (direito comunitário derivado), cujas características são particulares, pois as normas comunitárias não precisam ser transformadas em direito interno para vigorarem no território dos Estados-Membros, uma vez que se impõem por si. Ademais, a validade delas encontra-se no momento inicial em que os Estados-Membros efetuaram a transferência de soberania. Para esta adaptação, os dos Estados-Membros alteraram as suas Constituições. Cf. QUADROS, Inês. A Função Subjetiva da Competência Prejudicial do TJ das Comunidades Europeias. Coimbra: Almedina, 2006, p. 21, 34 e 35.

10 BORCHARDT, Klaus-Dieter. $O A B C$ do Direito da União Europeia. Disponível em: <http://publications.europa.eu/resource/cellar/5d4f8cde-de25-11e7-a506-01aa75ed71a1.0015.01/DOC_1>. Acesso em: 12 abr. 2021. p. 48.

${ }^{11}$ Acórdão do TJCE em Walrave (1974) (UNIÃO EUROPEIA. Tribunal de Justiça. Acórdão. Acórdão de 12 de dezembro de 1974, Walrave, Case 36/74, ECLI:EU:C:1974:140. Disponível em: <https://eur-lex.europa.eu/legal-
} 
utilizou dos institutos de direito comunitário existentes para decidir sobre as questões que lhe foram colocadas na construção do sistema, o que resultou no entendimento de que o esporte estava sujeito à legislação da UE sempre que praticado como atividade econômica ${ }^{12}$, o que impactou em uma maior proteção aos profissionais vinculados ao esporte.

Nos anos 2000, dois $\operatorname{casos}^{13}$ confirmaram que o esporte está sujeito à legislação da UE, firmando essa importante posição, na medida em que a UE continuava carente de uma base legal nos tratados para desenvolver uma política desportiva comum ${ }^{14}$.

É fato, no entanto, que a relação entre o esporte e a UE tem relevância para além dos limites da regulação da atividade econômica, pois a UE tem aspirações sociais e culturais e o esporte seria um dos instrumentos através dos quais estes objetivos podem ser alcançados ${ }^{15}$.

Apenas em 2009, com o Tratado de Lisboa ${ }^{16}$, o esporte foi explicitamente reconhecido como uma temática de abordagem para a União Europeia UE, nos tratados constitutivos. É marco notável na formação da legislação da UE, mas na verdade tem um âmbito limitado ${ }^{17}$, pois o artigo $6^{\circ}$ prevê que a UE dispõe de competência para desenvolver ações destinadas a apoiar, coordenar ou completar a ação dos Estados-Membros e o artigo 165', item 1, afirma que a UE contribuirá para a promoção dos aspectos europeus do esporte e, no item 2, dispõe que a UE desenvolverá a dimensão europeia do esporte.

content/EN/ALL/?uri=CELEX\%3A61974CJ0036>. Acesso em: 26 out. 2021.). Acordão do TJCE em Donà (1976) (UNIÃO EUROPEIA. Tribunal de Justiça. Acórdão. Acórdão de 14 de julho de 1976, Donà, Case 13/76, ECLI:EU:C:1976:115.

Disponível em:

https://curia.europa.eu/juris/showPdf.jsf?text=\&docid=89406\&pageIndex=0\&doclang=PT\&mode=lst\&dir=\&oc $\mathrm{c}=$ first \& part $=1 \& \mathrm{cid}=25112558>$. Acesso em: 26 out. 2021.)

${ }^{12} \mathrm{Na}$ acepção do antigo artigo $2^{\circ}$ do TCEE, hoje TFUE.

${ }^{13}$ Acórdão do TJCE em Deliège (2000) (UNIÃO EUROPEIA. Tribunal de Justiça. Acórdão. Acórdão de 11 de abril de 2000, Deliège, C-51/96 e C-191/97, ECLI:EU:C:2000:199. Disponível em: < https://eurlex.europa.eu/legal-content/HR/TXT/?uri=CELEX:61996CJ0051>. Acesso em: 26 out. 2021.) Acórdão do TJCE em Lehtonen (2000) (UNIÃO EUROPEIA. Tribunal de Justiça. Acórdão. Sexta Secção. Acórdão de 13 de abril de 2000, Lehtonen, C-176/96, ECLI:EU:C:2000:201. Disponível em: <https://eur-lex.europa.eu/legalcontent/EN/TXT/?uri=ecli:ECLI:EU:C:2000:201>. Acesso em: 26 out. 2021.).

${ }^{14}$ PARRISH, Richard. Sports law and policy in the European Union. Manchester: Manchester University Press, 2003, p. 24.

${ }^{15}$ PARRISH, Richard. Judicial intervention and sporting autonomy: Defining the territories of European Union involvement in sport. European Sport Management Quarterly, v. 2, n. 4, 2002, p. 296. Disponível em: <https://www.tandfonline.com/doi/abs/10.1080/16184740208721930>. Acesso em: 26 out. 2021.

${ }^{16}$ Artigos $2^{\circ}$ e $149^{\circ}$. UNIÃO EUROPEIA. Tratado de Lisboa, que altera o Tratado da União Europeia e o Tratado que institui a Comunidade Europeia. Disponível em: <https://eur-lex.europa.eu/legalcontent/PT/TXT/HTML/?uri=OJ:C:2007:306:FULL\&from=PT\#>. Acesso em: 26 out. 2021. Os respectivos artigos encontram-se na revisão daquele tratado pelo TFUE, nos artigos $6^{\circ}$ e $165^{\circ}$. UNIÃO EUROPEIA. Tratado sobre $o$ Funcionamento da União Europeia. Disponível em: <https://eurlex.europa.eu/resource.html?uri=cellar:9e8d52e1-2c70-11e6-b497-

01aa75ed71a1.0019.01/DOC_3\&format=PDF>. Acesso em: 26 out. 2021.

${ }^{17}$ SIEKMANN, Robert C.R. Introduction to International and European Sports Law. Haia: Asser Press, 2012 , p. 14. 
Além da inclusão explícita do esporte, o Tratado de Lisboa ${ }^{18}$ representou, também, um passo decisivo na criação de uma ordem jurídica de direitos fundamentais na UE, pois instituiu um novo artigo ${ }^{19}$ sobre os direitos fundamentais, que declara a Carta dos Direitos Fundamentais da União Europeia de 2000 um documento com força vinculante, no mesmo nível dos tratados constitutivos, isto é, eleva a Carta ao patamar de direito primário da UE.

A Carta dos Direitos Fundamentais da União Europeia, por sua vez, contempla vastas matérias como a dignidade humana, liberdades, igualdade, solidariedade, direitos do cidadão e justiça de forma ampla. É instrumento inovador de muitas formas, nomeadamente, afasta, entre outras questões, a idade e a orientação sexual como motivos de discriminação, sendo que os direitos que reconhece são concedidos a todos, independentemente da nacionalidade ou do estatuto ${ }^{20}$.

A partir desse momento, a UE, numa nova etapa de sua construção, avança, explicitamente, para uma fase humana, na qual preveem-se impactos para o fenômeno esportivo, pois os direitos fundamentais, ao fazerem parte do arcabouço comunitário, refletirão na visão do homem-atleta, que completará a visão do atleta, que fazia parte de uma engrenagem apenas econômica da UE.

Na revisão do Tratado de Lisboa, pelo Tratado de Funcionamento da União Europeia (TFUE), a legislação da UE permite que valores e considerações éticas sejam levados em consideração $^{21}$, o que é, também, uma nova e recente perspectiva para tratar do esporte na UE.

Assim, denota-se que o projeto do bloco europeu iniciou-se com um objetivo de integração econômica e avançou, ao longo do tempo, até sua vertente ética e de direitos fundamentais. Contudo, a UE não é uma estrutura acabada, mas antes um "sistema em construção" 22 , cujo arcabouço jurídico primário não regula de forma sistemática o esporte e

18 “Com o Tratado de Lisboa, a União Europeia e a Comunidade Europeia fundiram-se e a expressão 'Comunidade' vai sendo sistematicamente substituída pela expressão União”. BORCHARDT, Klaus-Dieter. $O A B C$ do Direito da União Europeia, 2017. Disponível em: http://publications.europa.eu/resource/cellar/5d4f8cde-de25-11e7a506-01aa75ed71a1.0015.01/DOC_1. Acesso em: 12 abr. 2021. p. 19. A abordagem constitucional fracassou e a Europa continua a legislar com tratados internacionais. Cf. PECEQUILO, Cristina Soreanu. A União Europeia os desafios, a crise e o futuro da integração. Rio de Janeiro: Elsevier, 2014, p. 83.

${ }^{19}$ Artigo $6^{\circ}$ do Tratado de Lisboa. UNIÃO EUROPEIA. Tratado de Lisboa, que altera o Tratado da União Europeia e o Tratado que institui a Comunidade Europeia. Disponível em: <https://eur-lex.europa.eu/legalcontent/PT/TXT/HTML/?uri=OJ:C:2007:306:FULL\&from=PT\#>. Acesso em: 26 out. 2021.

${ }^{20}$ Artigo $21^{\circ}$ da Carta dos Direitos Fundamentais da União Europeia. UNIÃO EUROPEIA. Carta dos Direitos Fundamentais da União Europeia. Disponível em: <https://eur-lex.europa.eu/legalcontent/PT/TXT/PDF/?uri=CELEX:12016P/TXT\&from=FR>. Acesso em: 26 out. 2021.

21 AZOULAI, Loic. The European Court of Justice and the duty to respect sensitive national interests. In: DAWSON, Mark; DE WITTE, Bruno; MUIR, Elise (Eds.). Judicial Activism at the European Court of Justice. Cheltenham: Edward Elgar, 2013, p. 180.

22 BORCHARDT, Klaus-Dieter. $O A B C$ do Direito da União Europeia. Disponível em: <http://publications.europa.eu/resource/cellar/5d4f8cde-de25-11e7-a506-01aa75ed71a1.0015.01/DOC_1>. Acesso em: 12 abr. 2021. p. 48. 
esse vácuo normativo foi completado, em parte, por decisões pontuais do TJUE, por meio do reenvio prejudicial, que interrelacionou os sistemas jurídicos supranacional e nacional.

\section{O TRIBUNAL DE JUSTIÇA DA UNIÃO EUROPEIA E O REENVIO PREJUDICIAL}

O TJUE, com sede em Luxemburgo, foi criado em 1951. Hoje, o TJUE é o órgão comunitário jurisdicional supremo da UE.

É importante afirmar que o TJUE não é hierarquicamente superior aos tribunais nacionais e não funciona como órgão recursal. O Poder Judiciário nacional de cada Estado continua com a sua competência interpretativa e de aplicação do direito comunitário.

O direito comunitário precisa ser compreendido de maneira unitária e uniforme, cabendo ao TJUE o papel de interpretá-lo mediante um sistema de cooperação clássico ${ }^{23}$, que é o reenvio prejudicial.

O reenvio prejudicial é um procedimento por meio do qual o TJUE pode ser provocado a responder questionamentos feitos por juízes nacionais dos Estados-Membros sobre a interpretação e a validade do direito comunitário ${ }^{24}$. O reenvio tem o objetivo de uniformizar o direito comunitário. Para que aquele instituto se realize, parte-se de dois pressupostos do próprio sistema, quais sejam: a aplicação descentralizada e a aplicabilidade direta das normas comunitárias $^{25}$.

O instrumento do reenvio prejudicial dá unidade ao direito comunitário e está inserido na história do processo de integração europeu.

A ordem jurídica da UE não constitui um sistema autossuficiente ${ }^{26}$ que possibilite a sua efetivação centralizada, tendo em vista a própria natureza do organismo, pois a efetivação descentralizada do direito comunitário, isto é, a execução da decisão judicial do TJUE pela esfera nacional é necessária, apesar das suas marcas supranacionais, uma vez que o sistema

23 UNIÃO EUROPEIA. Estatuto do Tribunal de Justiça da União Europeia. Disponível em: $<$ https://curia.europa.eu/jcms/upload/docs/application/pdf/2016-08/tra-doc-pt-div-c-0000-2016-20160698405_00.pdf>. Acesso em: 26 out. 2021.

${ }^{24}$ CORREIA, Emanuella Chagas Jaguar. O efeito vinculante do reenvio prejudicial na União Europeia: um caminho para desenvolver o direito comunitário. RSTPR, ano 2, n. 4, ago. 2014, p. 66. CHUMBINHO, João Paulo Da Cunha Rendeiro. A Evolução da Atividade Interpretativa do Juiz da União Europeia e a Aplicação das Teses de Hart e de Dworkin. Data Venia, ano 1, n. 1, jul./dez. 2012, p. 208. Disponível em: <https://www.datavenia.pt/ficheiros/edicao01/datavenia01_p189-222.pdf>. Acesso em: 26 out. 2021.

25 QUADROS, Inês. A Função Subjetiva da Competência Prejudicial do TJ das Comunidades Europeias. Coimbra: Almedina, 2006, p. 24.

26 BORCHARDT, Klaus-Dieter. $O A B C$ do Direito da União Europeia. Disponível em: http://publications.europa.eu/resource/cellar/5d4f8cde-de25-11e7-a506-01aa75ed71a1.0015.01/DOC_1. Acesso em: 12 abr. 2021. p. 141. 
comunitário deve respeito à soberania dos Estados-Membros, aqui representada pelos Judiciários nacionais. Ao TJUE caberá, precipuamente, a interpretação do direito comunitário, cabendo ao juiz nacional a aplicação das respectivas normas na resolução de litígios ${ }^{27}$.

A aplicabilidade direta do direito comunitário é o outro pressuposto para que o instrumento de interpretação uniforme ocorra, o que significa que o direito da UE cria obrigações e confere direitos, não só para as instituições da UE e para os Estados-Membros, mas também para os cidadãos da União ${ }^{28}$.

É nesse ambiente, que o procedimento do reenvio prejudicial tem o objetivo de uniformizar o direito comunitário, consoante previsto no artigo $267^{\circ}$ do TFUE, que dispõe:

O Tribunal de Justiça da União Europeia é competente para decidir, a título prejudicial:

a) Sobre a interpretação dos Tratados;

b) Sobre a validade e a interpretação dos atos adotados pelas instituições, órgãos ou organismos da União.

Sempre que uma questão desta natureza seja suscitada perante qualquer órgão jurisdicional de um dos Estados-Membros, esse órgão pode, se considerar que uma decisão sobre essa questão é necessária ao julgamento da causa, pedir ao Tribunal que sobre ela se pronuncie.

Sempre que uma questão desta natureza seja suscitada em processo pendente perante um órgão jurisdicional nacional cujas decisões não sejam suscetíveis de recurso judicial previsto no direito interno, esse órgão é obrigado a submeter a questão ao Tribunal.

$[\ldots]$

Nas alíneas a) e b) do artigo $267^{\circ}$, verifica-se que o TJUE atuará em questões relacionadas à interpretação e à validade do direito comunitário. De onde resultarão essas duas espécies de acórdãos: de interpretação e de validade.

Quanto à primeira espécie ${ }^{29}$, entende-se que interpretar é definir o sentido de uma disposição, quando esse sentido e o objeto da norma não resultam claramente do seu texto ${ }^{30}$. Da segunda espécie de reenvio resultam acórdãos sobre validade, esclarecendo-se que só o TJUE pode declarar a invalidade do direito comunitário ${ }^{31}$.

${ }^{27}$ CUNHA, Paulo Pitta. Direito Institucional da União Europeia. Coimbra: Almedina, 2004, p. 53.

28 BORCHARDT, Klaus-Dieter. O ABC do Direito da União Europeia. Disponível em: <http://publications.europa.eu/resource/cellar/5d4f8cde-de25-11e7-a506-01aa75ed71a1.0015.01/DOC_1>. Acesso em: 12 abr. 2021. p. 142. Nem todas as normas comunitárias têm a característica da aplicabilidade direta, pois há repartição de competências entre a UE e os Estados. Cf. QUADROS, Inês. A Função Subjetiva da Competência Prejudicial do TJ das Comunidades Europeias. Coimbra: Almedina, 2006, p. 22.

${ }^{29}$ O termo "tratado" deve ser entendido de forma ampla. Cf. Acórdão do TCE de 8.2.1963, proc. 32/62, Col. p. 65, citado por CAMPOS, João Mota de. Direito Comunitário: Ordenamento Jurídico Comunitário. 2. ed. Lisboa: Fundação Calouste Gulbenkian, 1990, vol. II, p. 396.

${ }^{30}$ Da jurisprudência do Tribunal decorre, ainda, que o trabalho de interpretação relaciona-se com a determinação dos critérios e dos efeitos da aplicabilidade direta; com a afirmação do primado do direito comunitário e com a determinação do preenchimento de lacunas do direito comunitário, dentre outras matérias. Ibidem, p. 434 e 435.

${ }^{31}$ Ibidem, p. 119. 
Ambas as espécies de reenvio não podem ter como objeto o direito nacional, pois a interpretação e a validade só são feitas em face do direito comunitário ${ }^{32}$, seja de norma de tratado ou de norma de direito derivado.

O TJUE não resolve a questão do litígio em si e nem conhece dos fatos, cabendo-lhe, apenas, proclamar o direito de forma abstrata ${ }^{33}$ e atribuir critérios de decisão ${ }^{34}$, competindo, desta forma, ao juiz nacional aplicar o direito comunitário ao caso.

Conforme se depreende do primeiro parágrafo do artigo $267^{\circ}$ do TFUE, apenas podem formular pedidos de reenvio prejudicial os órgãos jurisdicionais ${ }^{35}$ dos Estados-Membros ${ }^{36}$.

O reenvio é feito com base numa dúvida, que deve ser resolvida, preliminarmente, à decisão da causa originária e essa dúvida, normalmente, é apresentada sob a forma de perguntas $\operatorname{diretas}^{37}$. Não há, contudo, um procedimento formal escrito sobre o reenvio prejudicial, sendo possível apresentá-lo quantas vezes o juiz nacional considerar necessário ${ }^{38}$.

As questões prejudiciais podem, ainda, ser obrigatórias ou facultativas.

Para que sejam obrigatórias, deve-se estar perante, primeiramente, a uma dúvida. Depois verifica-se, se há uma das duas hipóteses de obrigatoriedade: (i) se a questão não tem recurso judicial previsto no direito nacional ou (ii) se ela se refere a ato declarado inválido ${ }^{39}$, isto porque só ao TJUE cabe afastar as disposições do direito da $\mathrm{UE}^{40}$.

O órgão jurisdicional só pode subtrair-se àquela obrigação de formular o reenvio, $a$ contrario sensu, se não subsistir qualquer dúvida, se houver recurso interno, se o juiz nacional

32 BORCHARDT, Klaus-Dieter. $O A B C$ do Direito da União Europeia. Disponível em: <http://publications.europa.eu/resource/cellar/5d4f8cde-de25-11e7-a506-01aa75ed71a1.0015.01/DOC_1>. Acesso em: 12 abr. 2021. p. 132. CAMPOS, João Mota de. Op. Cit., p. 438.

${ }^{33}$ CAMPOS, João Mota de. Op. cit., p. 435 e 436.

${ }^{34}$ QUADROS, Inês. A Função Subjetiva da Competência Prejudicial do TJ das Comunidades Europeias. Coimbra: Almedina, 2006, p. 126.

${ }^{35}$ O TJUE enunciou critérios para qualificar um órgão nacional com jurisdição para efeitos de reenvio prejudicial, dentre eles estão a origem legal do órgão em causa, a permanência e o caráter obrigatório da jurisdição, excluindo os tribunais arbitrais privados desta lista. O TCE no AC. de 23.3.1982 afirmou que um tribunal arbitral não é uma jurisdição nacional autorizada a recorrer ao TJ (proc. 102/81). CAMPOS, João Mota de. Op. cit., p. 401.

${ }^{36}$ Só ao juiz nacional cabe formular a questão a ser submetida por meio do recurso prejudicial. As partes podem apenas procurar convencer o juiz de que se está frente a uma questão prejudicial. Difícil, desta forma, argumentar que o reenvio prejudicial seja um direito das partes. Está-se diante de uma prerrogativa do juiz. É possível, em outras palavras, configurar o reenvio como um interesse legítimo do particular correlato a um poder-dever do juiz nacional. Cf. QUADROS, Inês. Op. cit., p. 127-129.

${ }^{37}$ CORREIA, Emanuella Chagas Jaguar. O efeito vinculante do reenvio prejudicial na União Europeia: um caminho para desenvolver o direito comunitário. RSTPR, ano 2, n. 4, ago. 2014, p. 68.

${ }^{38} \mathrm{O}$ TJUE pode solicitar todos os documentos que considere oportunos para deliberar sobre as perguntas, bem como solicitar às partes do processo qualquer tipo de informação que o Tribunal considere necessária.

39 BORCHARDT, Klaus-Dieter. $O A B C$ do Direito da União Europeia. Disponível em: <http://publications.europa.eu/resource/cellar/5d4f8cde-de25-11e7-a506-01aa75ed71a1.0015.01/DOC_1>. Acesso em: 12 abr. 2021. p. 134.

${ }^{40}$ Ibidem, p. 119. 
julgar o ato comunitário válido ${ }^{41} \mathrm{ou}$, ainda, se a questão já foi objeto de um acórdão de reenvio prejudicial do TJUE, o que cria precedente, projetando influência ${ }^{42}$ para todo o sistema.

O resultado da análise do TJUE quanto ao reenvio será um acórdão prolatado, que tem efeito vinculante e será obrigatório para o caso sub judice, bem como para os outros que venham a ser julgados, posteriormente, por todos os tribunais dos Estados-Membros ${ }^{43}$, numa postura de precedente obrigatório.

É certo, entretanto, que o TJUE sempre poderá alterar a sua decisão interpretativa, a propósito de novos $\operatorname{casos}^{44}$.

Se houver a recusa do órgão jurisdicional em relação à obrigação de reenvio, será possível sustentar a tese de que tal ato implicaria descumprimento de obrigação estipulada em tratado, o que poderia levar à propositura de uma ação por incumprimento contra o EstadoMembro $^{45}$, isto porque o TJUE já reconheceu o tema da responsabilidade dos Estados-Membros por violação do direito da $\mathrm{UE}^{46}$.

Cabe às autoridades nacionais aplicarem o direito comunitário e executarem as decisões do TJUE, segundo as normas de direito nacional. Há, desta forma, cooperação entre a autoridade supranacional e os juízes nacionais com vista a assegurar a unidade de interpretação

\footnotetext{
${ }^{41}$ CAMPOS, João Mota de. Direito Comunitário: Ordenamento Jurídico Comunitário. 2. ed. Lisboa: Fundação Calouste Gulbenkian, 1990, vol. II, p. 412.

${ }^{42}$ CUNHA, Paulo Pitta. Direito Institucional da União Europeia. Coimbra: Almedina, 2004, p. 84.

${ }^{43}$ CORREIA, Emanuella Chagas Jaguar. O efeito vinculante do reenvio prejudicial na União Europeia: um caminho para desenvolver o direito comunitário. RSTPR, ano 2, n. 4, ago. 2014, p. 79.

${ }^{44}$ Um importante exemplo de alteração de entendimento diz respeito às restrições à autonomia do fenômeno desportivo e do direito dos Estados que podem surgir quanto à regulamentação da matéria, pois num primeiro momento o TJUE decidiu, através do reenvio prejudicial, que o direito comunitário seria aplicável ao esporte, na medida em que esse era uma atividade econômica, na acepção do artigo $2^{\circ}$ do TCEE, conforme os acórdãos do TJCE em Walrave (1974) e Donà (1976), consoante mencionado na nota 11. Já em outra decisão de 2006, que não é resultado de reenvio prejudicial, o TJUE abordou a possibilidade de submissão das regras de antidopagem das Federações Desportivas Internacionais com as regras de concorrência da UE, conforme o caso C-519/04 MecaMedina \& Majcen v. Commission [2006] E.C.R. II-3291 (UNIÃO EUROPEIA. Tribunal de Justiça. Acórdão. Acórdão de 18 de julho de 2006, Meca-Medina e Majcen v. Commission, Case C-519/04, ECLI:EU:C:2006:492. Disponível em: < https://eur-lex.europa.eu/legalcontent/EN/TXT/?uri=CELEX\%3A62004CJ0519\&qid=1640127895882>.). Com essa decisão, não só regras esportivas com caráter econômico estão sujeitas ao direito do bloco. O TJUE deixa claro que a avaliação sobre a subsunção de uma regra esportiva à legislação da UE só pode ser feita caso a caso.

45 “Ação por incumprimento é possível se um Estado-Membro não tomar as medidas necessárias para a execução do acórdão. A Comissão dispõe da possibilidade de condenar, por incumprimento do tratado, um Estado que já tenha ignorado um acórdão do Tribunal de Justiça obrigando ao pagamento de uma quantia fixa e/ou sanção pecuniária compulsória.” BORCHARDT, Klaus-Dieter. $O A B C$ do Direito da União Europeia. Disponível em: <http://publications.europa.eu/resource/cellar/5d4f8cde-de25-11e7-a506-01aa75ed71a1.0015.01/DOC_1>. Acesso em: 12 abr. 2021. p. 127.

46 Contudo, existiriam algumas dificuldades em relação àquela tese, já que se tem que levar em conta a independência do Poder Judiciário nacional e o fato de que, para esse ser responsabilizado, sempre será necessário provar a sua arbitrariedade no julgamento. Além disso, a execução de uma decisão dessa natureza estaria circunscrita ao sistema legal interno do Estado-Membro, uma vez que o TJUE não conseguiria executá-la, tendo em vista a ausência de hierarquia entre a ordem jurídica da UE e a ordens jurídicas nacionais. Ibidem, p. 134-136.
} 
do direito comunitário e a permitir a sua aplicação uniforme pelos Estados-Membros ${ }^{47}$, sendo o reenvio o instrumento que efetiva essa interação.

Este diálogo entre as ordens jurídicas inicia-se com a atuação do juiz nacional por meio de um despacho e termina com uma decisão proferida pelo TJUE, sob a forma de acórdão a ser aplicado pelo juiz nacional ${ }^{48}$.

O reenvio combina elementos de uma opinião consultiva e de uma decisão judicial ${ }^{49}$. Não há, portanto, um processo contencioso.

Além da função de manter a uniformidade do direito comunitário europeu, o instituto do reenvio tem, também, a função de criar direito por meio do método teleológico de interpretação, com base nos objetivos dos $\operatorname{tratados}^{50}$ que regem as operações do direito da $\mathrm{UE}^{51}$, nas situações em que:

[...] as decisões do TCE (hoje TJUE) pareceram, em muitos casos, exceder o mero nível de interpretação para se situar no plano da criação de direito.

Tais decisões são verdadeiras fontes materiais de direito comunitário, pois nem sequer estão marcadas pela relatividade do caso julgado na medida em que, pela via do processo interpretativo, definem princípios ou exprimem o sentido de normas comunitárias $[\ldots] .^{52}$

No caso da temática esportiva, em que não havia fonte comunitária primária sobre o assunto até 2009, o TJUE utilizou os objetivos do bloco de integração, constantes nos tratados, para proferir decisões sobre atividade desportiva, mediante método teleológico ${ }^{53}$. A partir do

\footnotetext{
${ }^{47}$ CUNHA, Paulo Pitta. Direito Institucional da União Europeia. Coimbra: Almedina, 2004, p. 53.

${ }^{48}$ CAMPOS, João Mota de. Direito Comunitário: Ordenamento Jurídico Comunitário. 2. ed. Lisboa: Fundação Calouste Gulbenkian, 1990, vol. II, p. 421.

49 CORREIA, Emanuella Chagas Jaguar. O efeito vinculante do reenvio prejudicial na União Europeia: um caminho para desenvolver o direito comunitário. RSTPR, ano 2, n. 4, ago. 2014, p. 79.

${ }^{50} \mathrm{O}$ artigo $2^{\circ}$ do TCE dispunha que "A Comunidade tem como missão promover pelo estabelecimento do mercado comum e pela aproximação progressiva das políticas econômicas dos estados-membros, um desenvolvimento harmonioso das atividades econômicas no seio da comunidade [...]". Norma que atribui aos órgãos da União uma ampla liberdade. Cf. CHUMBINHO, João Paulo Da Cunha Rendeiro. A Evolução da Atividade Interpretativa do Juiz da União Europeia e a Aplicação das Teses de Hart e de Dworkin. Data Venia, ano 1, n. 1, p. 189-221, jul./dez. 2012. Disponível em: 〈https://www.datavenia.pt/ficheiros/edicao01/datavenia01_p189-222.pdf〉. Acesso em: 26 out. 2021. p. 203.
}

${ }^{51}$ AZOULAI, Loic. The European Court of Justice and the duty to respect sensitive national interests. In: DAWSON, Mark; DE WITTE, Bruno; MUIR, Elise (Eds.). Judicial Activism at the European Court of Justice. Cheltenham: Edward Elgar, 2013, p. 180.

52 CAMPOS, João Mota de. Direito Comunitário: Ordenamento Jurídico Comunitário. 2. ed. Lisboa: Fundação Calouste Gulbenkian, 1990, vol. II, p. 151.

${ }^{53}$ Sobre a incompletude dos tratados e a atividade do TJUE, cf. CHUMBINHO, João Paulo Da Cunha Rendeiro. A Evolução da Atividade Interpretativa do Juiz da União Europeia e a Aplicação das Teses de Hart e de Dworkin. Data Venia, ano 1, n. 1, p. 189-221, jul./dez. 2012. Disponível em: <https://www.datavenia.pt/ficheiros/edicao01/datavenia01_p189-222.pdf>. Acesso em: 26 out. 2021. p. 203. Inclusive o autor refere-se a Hart, para fundamentar o processo de criação pelo Judiciário, em caso de indeterminação e incompletude do direito. Apesar das revisões dos tratados, o TJUE continua com domínios muito vastos. Op. cit., p. 204 e 213. 
Tratado de Lisboa, o esporte passou a fazer parte da temática comunitária, no nível primário de normas, bem como a Carta dos Direitos Fundamentais da União Europeia foi absorvida no mesmo nível dos tratados constitutivos, consoante já abordado. Ambos os fatos trazem como consequência, por um lado, o alargamento da perspectiva do TJUE sobre a temática desportiva; e, por outro, direciona o entendimento sobre o esporte para além das barreiras dos fatores de produção. Assim, a legislação da UE, permeada de valores e considerações éticas, será levada em consideração nas futuras decisões do TJUE sobre o esporte ${ }^{54}$.

No momento em que os juízes nacionais enviam ao Tribunal questões prejudiciais, indagando sobre a interpretação do direito comunitário, e aquelas questões são devolvidas com decisões com força vinculante de precedente, indubitavelmente, serão criadas normas, o que já foi chamado de "federalismo jurídico" $"$.

Desse modo, o reenvio prejudicial tem a função de interpretação, uniformização e criação do direito comunitário, que impacta em vários aspectos no sistema desportivo, especialmente quanto à autonomia desse fenômeno.

\section{EXEMPLO DE IMPACTO DA UNIFORMIZAÇÃO DO DIREITO COMUNITÁRIO NO ESPORTE}

O instrumento do reenvio relaciona-se com todos os subsistemas de direito, inclusive, com o do esporte. Menciona-se, assim, o acórdão do TJUE de 26 de outubro de $2017^{56}$, cujo pedido de decisão prejudicial foi apresentado no âmbito de um litígio entre a União de Bridge Inglesa (UBI) e a Administração Fiscal e Aduaneira do Reino Unido, a respeito da sujeição ao imposto sobre o valor acrescentado (IVA), que incidiria em relação à inscrição nas competições que a UBI organiza.

A norma a ser interpretada foi o artigo $132^{\circ}$, n. 1, m) da Diretiva 2006/112, que dispõe que há isenção de:

\footnotetext{
${ }^{54}$ AZOULAI, Loic. The European Court of Justice and the duty to respect sensitive national interests. In: DAWSON, Mark; DE WITTE, Bruno; MUIR, Elise (Eds.). Judicial Activism at the European Court of Justice. Cheltenham: Edward Elgar, 2013, p. 180.

${ }^{55}$ CAMPOS, João Mota de. Op. cit., p. 157.

${ }^{56}$ UNIÃO EUROPEIA. Tribunal de Justiça. Quarta Secção. Acórdão. Reenvio prejudicial Fiscalidade-Imposto sobre o valor acrescentado (IVA)-Diretiva 2006/112/CE-Conceito de “desporto". Processo C-90/16. 26 de outubro de 2017. Disponível em: <https://eur-lex.europa.eu/legalcontent/PT/TXT/HTML/?uri=CELEX:62016CJ0090\&from=EN>. Acesso em: 12 abr. 2021.
} 
$[\ldots]$

m) Determinadas prestações de serviços estreitamente relacionadas com a prática de desporto ou de educação física, efetuadas por organismos sem fins lucrativos a pessoas físicas, que pratiquem desporto ou educação física;

$[\ldots]$

A UBI é uma instituição nacional sem fins lucrativos, responsável pela regulamentação e pelo desenvolvimento do bridge duplicado na Inglaterra, sendo esse jogo de cartas praticado em competições nacionais e internacionais. Os jogadores, por sua vez, pagam a inscrição para participarem das competições e, sobre esse valor, há incidência de IVA. Por considerar que os referidos valores deviam ser isentos do tributo, nos termos do artigo $132^{\circ}, \mathrm{n} .1$, alínea $\mathrm{m}$ ), da Diretiva em causa, a UBI pediu à Administração Fiscal a devolução do imposto, mas o pedido foi indeferido.

A UBI sustentou que "esporte", na acepção da Diretiva, não tem, necessariamente, de conter um componente de atividade física significativo, uma vez que o dispositivo tem por finalidade favorecer as atividades benéficas à saúde física, sendo que a atividade intelectual é tão importante quanto a atividade física para aquele fim.

A Administração Fiscal opôs-se à argumentação, defendendo que o entendimento pretendido é contrário ao princípio da interpretação estrita das isenções tributárias.

O Tribunal Superior Secção Tributária decidiu suspender a instância e submeter ao TJUE as seguintes questões prejudiciais:

1) Quais as características essenciais de uma atividade para ser considerada um "esporte", conforme a Diretiva 2006/112? A atividade envolvida deve ter um componente físico significativo que seja determinante para o seu resultado ou é suficiente que tenha um componente mental significativo que seja determinante para o seu resultado?

2) Deve o bridge duplicado ser considerado um "esporte" na acepção da Diretiva $2006 / 112$ ?

Conforme se verifica, o TJUE não é chamado a determinar o significado do conceito de esporte em geral, mas a interpretá-lo no âmbito da Diretiva relativa ao IVA e, em especial, da disposição desta Diretiva em matéria de isenções.

$\mathrm{Na}$ falta de uma definição do conceito de esporte, na Diretiva 2006/112, a determinação do significado e do alcance deste termo foi fixada, segundo a jurisprudência constante do TJUE, de acordo com o seu sentido habitual na linguagem corrente. 
As atividades que correspondem ao sentido habitual do termo "esporte", são as que se caracterizam por um componente físico não insignificante, sem se alargar a todas as atividades que podem ser associadas ao conceito, segundo o TJUE.

O fato de uma atividade favorecer a saúde física e mental não seria, por si só, um elemento suficiente para concluir que é abrangida pelo conceito de esporte.

O TJUE entendeu, também, que a circunstância de se realizarem competições de uma atividade, que favorece o bem-estar físico e mental, não permite que se chegue a uma conclusão diferente.

Segundo o TJUE, uma interpretação do âmbito da isenção prevista no $\operatorname{artigo} 132^{\circ}, \mathrm{n}$. 1, alínea m), da referida Diretiva, que consista em incluir atividades que comportam um componente físico insignificante, constitui uma leitura extensiva do referido dispositivo.

Decorre, assim, da redação e da interpretação da Diretiva 2006/112, que o dispositivo só se refere a atividades que se caracterizem por um componente físico significativo.

Atendendo a todas estas considerações, ao responder às questões submetidas, o TJUE entendeu que uma atividade, como o bridge duplicado, que se caracteriza por um componente físico que parece ser insignificante, não é abrangida pelo conceito de "esporte", na acepção do artigo.

Portanto, o TJUE interpretou, sistematicamente, o termo "esporte" no âmbito das isenções tributárias e criou precedente.

Verifica-se, a partir desse precedente, a possibilidade de haver uma infinidade de questionamentos por parte dos juízes nacionais a respeito da interpretação e, no caso, da aplicação de normas comunitárias, para as quais não haja entendimento comunitário consolidado quanto às atividades esportivas regulamentadas por práticas do mercado e por entidades desportivas ou, ainda, disciplinadas pelo direito dos Estados-Membros individualmente, como é o caso dos jogos de tabuleiro e dos jogos eletrônicos, os quais possuem competições, que, inevitavelmente, movimentam a atividade econômica. Assim, o TJUE pode ser chamado a se manifestar por meio do reenvio prejudicial e classificá-las, ou não, como práticas desportivas, num diálogo sistêmico entre diferentes ordens. 


\section{OS DIÁLOGOS ENTRE JUÍZES E O ESPORTE NA UNIÃO EUROPEIA}

O direito desportivo evoluiu de tal maneira que não há dúvida de que ele configura um subsistema com especificidades ${ }^{57}$. Há uma ordem jurídica que o envolve ${ }^{58}$ e essa ordem pode relacionar-se com outras ordens jurídicas, como as abordadas neste artigo, nos níveis nacional e supranacional.

No direito comunitário, a lex sportiva depara-se com restrições impostas mediante mecanismos legais de controle superiores aos dos Estados isolados. Nesse contexto de controle, encontra-se o reenvio prejudicial. O caso Bosman ${ }^{59}$ é exemplo da interferência do direito comunitário na autonomia esportiva, também, por meio do reenvio prejudicial ${ }^{60}$.

No caso Bosman, o TJUE reforçou a decisão de que a prática do esporte é passível de regulação pela ordem comunitária europeia porque é considerada atividade econômica ${ }^{61}$, tratou da livre circulação de jogadores de futebol no bloco e exerceu profundo efeito nas regras de transferência das ligas de futebol da UE, além de banir as restrições a estrangeiros nas ligas nacionais.

A relação entre o reenvio e o esporte faz parte dos acontecimentos contemporâneos, como se tem visto a respeito da discussão sobre a criação da "Super Liga", anunciada como uma competição formada por 12 dos principais clubes de futebol europeus ${ }^{62}$, que poderia rivalizar com o campeonato europeu conhecido como "Liga dos Campeões".

O Tribunal Comercial de Madri foi chamado a decidir sobre a matéria e encaminhou ao TJUE questionamentos a respeito através do reenvio prejudicial ${ }^{63}$, pois a União das

\footnotetext{
${ }^{57}$ FARIA, Tiago Silveira de. LEX FIFA: autonomia e poder de uma ordem jurídica transnacional. $2016.186 \mathrm{f}$. Dissertação (Mestrado) - Curso de Programa de Pós-Graduação em Direito, Universidade do Vale do Rio dos Sinos, São Leopoldo, 2016, p. 68.

${ }^{58}$ NEGÓCIO, Ramón de Vasconcelos. Lex Sportiva: da Eficácia Jurídica aos Problemas Transconstitucionais.

Direito.Unb, v. 1, n. 2, p. 133-159, jul./dez. 2014, p. 134.

${ }^{59}$ Bosman inicia um processo na Bélgica e o juiz, por meio do reenvio prejudicial, encaminha questões ao TJCE. Ao formular perguntas, faz um diálogo de fontes entre normas regulamentares do futebol com institutos de direito comunitário sobre livre circulação de trabalhadores; proibição de medidas impeditivas de livre concorrência e proibição de posição dominante. FORNASIER, Mateus de Oliveira; SILVA, Thiago dos Santos da. Direito Transnacional e Lex Sportiva: o caso Bosman e o diálogo reflexivo entre ordens jurídicas estatais e não estatais. Cadernos de Relações Internacionais, v. 8, n. 14, p. 55-91, jan./jun. 2017. Disponível em: <https://faculdadedamas.edu.br/revistafd/index.php/relacoesinternacionais/article/view/585>. Acesso em: 12 abr. 2021.

${ }^{60}$ FARIA, Tiago Silveira de. Op. cit., p. 94

${ }^{61}$ NEGÓCIO, Ramón de Vasconcelos. Op. cit., p. 152.

${ }^{62}$ Composta por Atlético de Madrid, Barcelona e Real Madrid; os italianos Internazionale de Milão, Juventus e Milan; e os ingleses Arsenal, Chelsea, Liverpool, Manchester City, Manchester United e Tottenham.

${ }^{63}$ Pedido de decisão prejudicial apresentado pelo Tribunal Comercial n. 17 de Madri (Espanha), em 27 de maio de 2021. Processo C-333/21, com as partes do processo principal European Superleague Company, S.L. e UEFA e FIFA. UNIÃO EUROPEIA. Tribunal de Justiça. Pedido de decisão prejudicial apresentado pelo Tribunal Comercial n. 17 de Madri (Espanha), em 27 de maio de 2021. Processo C-333/21, com as partes do processo
} 
Federações Europeias de Futebol (UEFA) ${ }^{64}$ e a Federação Internacional de Futebol (FIFA) tentaram impor sanções aos clubes que pretendiam compor a "Super Liga"

Os questionamentos dizem respeito aos artigos $101^{\circ}$ e $102^{\circ}$ do TFUE serem interpretados no sentido de proibirem um abuso de posição dominante, que consiste no fato de que a FIFA e a UEFA dispõem, nos seus estatutos, que seja exigida uma autorização prévia dessas entidades, que se atribuem competência exclusiva para organizar competições internacionais de clubes na Europa, para que uma terceira entidade, no caso a "Super Liga", estabeleça uma nova competição pan-europeia. O juiz nacional questiona, também, se as duas entidades podem ser detentoras de todos os direitos decorrentes das competições e restringir as liberdades fundamentais, com base na exigência de autorização prévia constante das disposições dos estatutos.

É evidente a preocupação com a livre concorrência em relação às competições, e caberá ao TJUE interpretar as normas dos artigos do TFUE. Para ficar mais evidente como o fenômeno esportivo convive com sistemas diferentes, a doutrina esclarece que:

[...] a lex sportiva concorre não apenas com as leis internas; as normas desportivas também devem, com efeito conformar-se aos imperativos do direito do bloco regional em questão, cuja observância impõe-se, em princípio, a todas as autoridades judicantes ${ }^{66}$.

Assim, decisão do TJUE pode interferir nas regras de associações esportivas e regulamentos desportivos, bem como no direito desportivo dos Estados-Membros por meio do reenvio prejudicial.

Isto porque o direito comunitário procurará imprimir certo equilíbrio nas relações que surgem do fenômeno esportivo, impondo, por exemplo, que uma federação esportiva internacional tenha que se submeter àquela ordem, caso o TJUE profira uma decisão com força

principal European Superleague Company, S.L. e UEFA e FIFA. Disponível em: <https://eur-lex.europa.eu/legalcontent/PT/TXT/?uri=CELEX:62021CN0333>. Acesso em: 26 de outubro de. 2021.

${ }^{64}$ A UEFA é uma associação regida pela lei suíça, reconhecida pela FIFA, incluindo entre seus membros as federações nacionais de futebol do continente europeu que são obrigadas a cumprir os estatutos, regulamentos e decisões da FIFA. Sua missão é lidar com todas as questões relativas ao futebol europeu, promovê-lo e monitorar seu desenvolvimento, bem como organizar competições internacionais a nível europeu, incluindo a "Liga dos Campeões" e a Liga Europa. Cf. o dispositivo da decisão de reenvio prejudicial caso C-299/15. UNIÃO EUROPEIA. Tribunal de Justiça. Ordonnance de la Cour. Neuvième Chambre. Ordonnance de 16 de julho de 2015, Striani v. UEFA e URBSFA, C-299/15, ECLI:EU:C:2015:519. Disponível em: $<$ https://curia.europa.eu/juris/document/document_print.jsf;jsessionid=9ea7d2dc30d59058948bba904ac69f1bb0 780651571e.e34KaxiLc3qMb40Rch0SaxuQbNv0?doclang=FR\&text=\&pageIndex $=0 \&$ part $=1 \&$ mode=DOC\&do cid $=166101 \&$ occ $=$ first \&dir $=\&$ cid $=869346>$. Acesso em: 26 out. 2021.

${ }^{65}$ HISSEL, Martin. SUPER LEAGUE - La CJUE saisie d'un renvoi préjudiciel. Elegis, 14 maio 2021. Disponível em: <https://www.elegis.be/fr/nouvelle/super-league-la-cjue-saisie-dun-renvoi-prejudiciel>. Acesso em: 26 out. de 2021.

${ }^{66}$ NICOLAU, Jean Eduardo. Direito Internacional Privado do Esporte. São Paulo: Quartier Latin, 2018, p. 389. 
de precedente contra aquela federação ${ }^{67}$, o que, na prática, deixaria a entidade federativa sem ter como sustentar sanções a todos os membros da UE, caso viesse a se opor a uma restrição imposta judicialmente.

Há, também, clara possibilidade de restrição do fenômeno desportivo pelo direito desportivo nacional, cuja natureza é híbrida ${ }^{68}$, bem como pela interação desse direito com o direito comunitário, na medida em que, atualmente, a perspectiva do esporte no bloco europeu é, ainda, muito pautada nas quatro liberdades e livre concorrência, que são temas fortemente influenciados por preocupações de interesse público e privado ${ }^{69}$.

A ordem comunitária, por meio do reenvio, interfere na ordem desportiva por entender que há caráter econômico e concorrencial no fenômeno desportivo ${ }^{70}$, fazendo um paralelo entre direito da concorrência ${ }^{71}$ e figuras típicas do esporte ${ }^{72}$.

Verifica-se que a construção da UE partiu de uma integração setorizada, no pós-guerra, tornou-se um arcabouço legal econômico, mas, atualmente, possui dimensões políticas de cidadania europeia ${ }^{73}$ e direitos fundamentais comuns, que refletem em todos os subsistemas.

Desta forma, portanto, é possível vislumbrar a invocação dos direitos fundamentais em face dos regulamentos desportivos privados, principalmente quando houver desequilíbrio entre os sujeitos envolvidos na relação esportiva, em que uma das partes pretende regular,

\footnotetext{
${ }^{67}$ BAYER, Rodrigo Stenmann. As Organizações Internacionais Esportivas nas Cortes Europeias. Disponível em: $<$ https://emporiododireito.com.br/leitura/as-organizacoes-internacionais-esportivas-nas-cortes-europeias1508155077>. Acesso em: 12 abr. 2021,

68 "O direto desportivo deixou de ser entendido apenas a partir de uma perspectiva de direito privado, pois apresenta, ao contrário, uma natureza mista, na qual um quadro regulamentar com base na autonomia privada interage com as normas de direito público". Tradução livre de CASINI, Lorenzo. Sports Law: A Global Legal Order? Law \& Society Forum. Honolulu, HI, 2012. Disponível em: http://es.globallawpress.org/wpcontent/uploads/Casini-Sports-Law.pdf. Acesso em: 26 out. 2021, p. 18. Isto sem contar que os Estados podem ter concepções diferentes a respeito do direito desportivo, pois há países que adotaram modelo de legislação esportiva intervencionista e outros não intervencionista. O primeiro é aquele que contém legislação específica sobre uma parte significativa do movimento desportivo nacional e todos os outros modelos de legislação esportiva são considerados não intervencionistas. SIEKMANN, Robert; SOEK, Janwillem. Models of sport governance in the European Union: the relationship between state and sport authorities. The International Sports Law Journal, n. 34, Jul./Oct. $2010, \quad$ p. $\quad 93 . \quad$ Disponível $<$ https://go.gale.com/ps/i.do?id=GALE\%7CA352250454\&sid=googleScholar\&v=2.1\&it=r\&linkaccess=abs\&iss $\mathrm{n}=15677559 \& \mathrm{p}=\mathrm{AONE} \& \mathrm{sw}=\mathrm{w} \& u$ serGroupName=anon\%7Ee2c28fed $>$. Acesso em: 26 out. 2021.

${ }^{69}$ PARRISH, Richard. Sports law and policy in the European Union. Manchester: Manchester University Press, 2003, p. 25.

${ }^{70}$ FARIA, Tiago Silveira de. LEX FIFA: autonomia e poder de uma ordem jurídica transnacional. $2016.186 \mathrm{f}$. Dissertação (Mestrado) - Curso de Programa de Pós-Graduação em Direito, Universidade do Vale do Rio dos Sinos, São Leopoldo, 2016, p. 95.

${ }^{71}$ Com conceitos como mercado relevante, monopólio e abuso de posição dominante.

${ }^{72}$ DUVAL, Antoine; ROMPUY, Ben Van. The Compatibility of Forced CAS Arbitration with EU Competition Law: Pechstein Reloaded. Disponível em: <https://www.competitionpolicyinternational.com/the-compatibilityof-forced-cas-arbitration-with-eu-competition-law-pechstein-reloaded/>. Acesso em: 12 abr. 2021.

${ }^{73}$ O Tratado de Maastricht (1992) reviu os tratados anteriores e institui, oficialmente, a cidadania europeia e o euro.
} 
unilateralmente, os direitos e liberdades dos atletas ${ }^{74}$. O TJUE passou a demonstrar que não há limite no que tange a matérias relativas à ordem desportiva ${ }^{75}$, especialmente quando estiverem em causa o direito de exercer a profissão e o princípio da dignidade da pessoa humana.

O TJUE já afirmou que "os direitos fundamentais garantidos na ordem jurídica da União Europeia são aplicáveis em todas as situações regidas pelo direito da União Europeia"76. Assim, o Tribunal declarou a aplicabilidade horizontal dos direitos consagrados na Carta dos Direitos Fundamentais, ou seja, os trabalhadores têm o direito de invocar as disposições da Carta em litígios entre eles e o seu empregador.

A observância dos direitos fundamentais deve ser uniforme, nas diferentes ordens jurídicas, independentemente da natureza da relação entre as partes ${ }^{77}$, desta forma o esporte está sujeito a todas as obrigações decorrentes das várias disposições dos tratados, sendo certo que a atividade desportiva na UE tem potencial de dar origem a litígios que justifiquem a aplicabilidade dos direitos fundamentais de forma horizontal entre as partes.

Portanto, o fenômeno esportivo está integrado aos movimentos associativos, ao direito estatal, ao direito comunitário e aos ditames da uniformização e interpretação do direito comunitário pelo TJUE, tendo o procedimento do reenvio prejudicial papel fundamental no diálogo entre sistemas.

\section{CONCLUSÃO}

O esporte, como um fenômeno que transcende fronteiras, nasceu da prática associativa com autonomia e autorregulamentação. No entanto, a prática associativa, que já convive com as limitações de ordem estatal, no continente europeu, relaciona-se com o direito comunitário supranacional.

Uma vez que não há política comum sistematizada com relação ao esporte na UE, a jurisprudência do TJUE tem papel fundamental e cumpre a função de emanar decisões com

\footnotetext{
${ }^{74}$ LEWANDOWISKI, Wojciech. Is Bauer the new Bosman? - The implications of the recent jurisprudence of the Court of Justice of the European Union for FIFA. VerfBlog, 06 jul. 2019. Disponível em: $<$ https://verfassungsblog.de/is-bauer-the-new-bosman-the-implications-of-the-recent-jurisprudence-of-the-courtof-justice-of-the-european-union-for-fifa/>. Acesso em: 12 abr. 2021.

75 BAYER, Rodrigo Stenmann. As Organizações Internacionais Esportivas nas Cortes Europeias, 2015. Disponível em: <https://emporiododireito.com.br/leitura/as-organizacoes-internacionais-esportivas-nas-corteseuropeias-1508155077>. Acesso em: 12 abr. 2021.

${ }^{76}$ No caso Bauer, parágrafo 52 da decisão. Este caso, embora não se refira diretamente aos direitos dos atletas, e sim ao direito a férias anuais remuneradas, define que esse direito é de caráter obrigatório e incondicional. Ibidem.

${ }^{77}$ LEWANDOWISKI, Wojciech. Op. cit.
} 
força vinculante, que limitam a autonomia associativa e o direito desportivo dos EstadosMembros.

A construção do que hoje é a UE partiu de uma integração setorizada, no pós-guerra, tornou-se um arcabouço econômico e, atualmente, possui dimensões políticas de cidadania europeia e de direitos fundamentais comuns, que se refletem em todas as regulamentações corporativas e em todos os subsistemas jurídicos, sendo certo, ainda, que o esporte, também, é uma das temáticas dos tratados da UE, o que resulta na elevação do nível de proteção dos atletas.

A fim de assegurar a unidade de interpretação do direito comunitário e a sua respectiva aplicação pelas jurisdições nacionais, o TJUE tendeu a assumir, substancialmente, um papel próximo de um legislador. Isto foi possível por meio do procedimento do reenvio prejudicial. Esse procedimento garante que, caso haja dúvida sobre a interpretação, ou seja suscitada a invalidade de uma norma de direito da UE, o juiz nacional suscite a questão junto do TJUE, para que esse decida sobre a sua interpretação e validade.

Nesse diapasão, o TJUE fornece uma visão geral pontual da aplicação do direito da UE sobre regras e normas desportivas e delimita a autonomia do fenômeno desportivo no nível associativo e no âmbito do direito estatal dos Estados-Membros.

O presente trabalho procurou demonstrar que a jurisprudência do TJUE tem forte potencial limitador da autonomia do movimento desportivo, sempre que constituir uma atividade econômica, bem como através de novas bases jurídicas, erguidas pós Tratado de Lisboa, as quais apesar de não indicarem uma política desportiva comum, envolvem muito mais do que a remoção de barreiras à livre circulação de fatores de produção.

$\mathrm{O}$ artigo traz decisão proferida pelo TJUE por meio do reenvio, que versa sobre a interpretação de norma comunitária à luz do termo "esporte", como exemplo da interação entre sistemas. Naquela decisão, o TJUE entendeu que apenas o fato de se realizarem competições, mesmo que favoreçam o bem-estar físico e mental, não permite concluir que tais competições sejam, efetivamente, relacionadas ao "esporte", caso não haja um componente físico significativo. Essa decisão tem potencial para afastar outras atividades, que possuam um desgaste físico discutível, da abrangência do que se entende por esporte, apesar da evidente movimentação da atividade econômica.

Além daquele caso, foram indicados outros, em que o reenvio faz a conexão entre sistemas, bem como o caso contemporâneo da "Super Liga", que promete envolver as próximas discussões sobre a restrição à autonomia esportiva. 
Portanto, o diálogo entre ordens jurídicas é possível e reflete-se na autonomia do fenômeno desportivo europeu, com restrições advindas da ordem supranacional, vez que há efeito vinculante das decisões de reenvio prejudicial do TJUE, impactando de forma a reequilibrar as relações esportivas, inclusive quando se referirem aos direitos fundamentais.

\section{REFERÊNCIAS}

ACCIOLY, Elizabeth. Mercosur \& Unión Europea: estrutura jurídico-institucional. 2. ed. Curitiba: Juruá, 1998.

AZOULAI, Loic. The European Court of Justice and the duty to respect sensitive national interests. In: DAWSON, Mark; DE WITTE, Bruno; MUIR, Elise (Eds.). Judicial Activism at the European Court of Justice. Cheltenham: Edward Elgar, 2013, p. 167-188.

BAYER, Rodrigo Stenmann. As Organizações Internacionais Esportivas nas Cortes Europeias, 2015. Disponível em: <https://emporiododireito.com.br/leitura/as-organizacoesinternacionais-esportivas-nas-cortes-europeias-1508155077>. Acesso em: 12 abr. 2021.

BORCHARDT, Klaus-Dieter. $O A B C$ do Direito da União Europeia, 2017. Disponível em: http://publications.europa.eu/resource/cellar/5d4f8cde-de25-11e7-a506-

01aa75ed71a1.0015.01/DOC_1. Acesso em: 12 abr. 2021.

CAMPOS, João Mota de. Direito Comunitário: O Direito Institucional. 6. ed. Lisboa: Fundação Calouste Gulbenkian, 1989. vol. I.

CAMPOS, João Mota de. Direito Comunitário: Ordenamento Jurídico Comunitário. 2. ed. Lisboa. Fundação Calouste Gulbenkian, 1990. vol. II.

CASINI, Lorenzo. Sports Law: A Global Legal Order? Law \& Society Forum. Honolulu, HI, 2012. Disponível em: <http://es.globallawpress.org/wp-content/uploads/Casini-SportsLaw.pdf>. Acesso em: 26 out. 2021.

CHUMBINHO, João Paulo Da Cunha Rendeiro. A Evolução da Atividade Interpretativa do Juiz da União Europeia e a Aplicação das Teses de Hart e de Dworkin. Data Venia, ano 1, n. 1, p. 189-221, jul./dez. 2012. Disponível em: <https://www.datavenia.pt/ficheiros/edicao01/datavenia01_p189-222.pdf>. Acesso em: 26 out. 2021.

CORREIA, Emanuella Chagas Jaguar. O efeito vinculante do reenvio prejudicial na União Europeia: um caminho para desenvolver o direito comunitário. RSTPR, ano 2, n. 4, ago. 2014, p. $65-82$.

CUNHA, Paulo Pitta. Direito Institucional da União Europeia. Coimbra: Almedina, 2004. 
DUVAL, Antoine; ROMPUY, Ben Van. The Compatibility of Forced CAS Arbitration with EU Competition Law: Pechstein Reloaded. Disponível em: $<$ https://www.competitionpolicyinternational.com/the-compatibility-of-forced-cas-arbitrationwith-eu-competition-law-pechstein-reloaded/>. Acesso em: 12 abr. 2021.

FARIA, Tiago Silveira de. LEX FIFA: autonomia e poder de uma ordem jurídica transnacional. 2016. 186 f. Dissertação (Mestrado) - Curso de Programa de Pós-Graduação em Direito, Universidade do Vale do Rio dos Sinos, São Leopoldo, 2016.

FORNASIER, Mateus de Oliveira; SILVA, Thiago dos Santos da. Direito Transnacional e Lex Sportiva: o caso Bosman e o diálogo reflexivo entre ordens jurídicas estatais e não estatais. Cadernos de Relações Internacionais, v. 8, n. 14, p. 55-91, jan./jun. 2017. Disponível em: $<$ https://faculdadedamas.edu.br/revistafd/index.php/relacoesinternacionais/article/view/585>. Acesso em: 12 abr. 2021.

HISSEL, Martin. SUPER LEAGUE - La CJUE saisie d'un renvoi préjudiciel. Elegis, 14 maio 2021. Disponível em: <https://www.elegis.be/fr/nouvelle/super-league-la-cjue-saisie-dunrenvoi-prejudiciel>. Acesso em: 26 out. 2021.

LEWANDOWISKI, Wojciech. Is Bauer the new Bosman? - The implications of the recent jurisprudence of the Court of Justice of the European Union for FIFA. VerfBlog, 06 jul. 2019. Disponível em: <https://verfassungsblog.de/is-bauer-the-new-bosman-the-implications-of-therecent-jurisprudence-of-the-court-of-justice-of-the-european-union-for-fifa/> . Acesso em: 12 abr. 2021.

NEGÓCIO, Ramón de Vasconcelos. Lex Sportiva: da Eficácia Jurídica aos Problemas Transconstitucionais. Direito.Unb, v. 1, n. 2, p. 133-159, jul./dez. 2014.

NICOLAU, Jean Eduardo. Direito Internacional Privado do Esporte. São Paulo: Quartier Latin, 2018.

PARRISH, Richard. Judicial intervention and sporting autonomy: Defining the territories of European Union involvement in sport. European Sport Management Quarterly, v. 2, n. 4, p. 296-307, 2002. Disponível em: <https://www.tandfonline.com/doi/abs/10.1080/16184740208721930>. Acesso em: 26 out. 2021.

PARRISH, Richard. Sports law and policy in the European Union. Manchester: Manchester University Press, 2003.

PECEQUILO, Cristina Soreanu. A União Europeia - os desafios, a crise e o futuro da integração. Rio de Janeiro: Elsevier, 2014.

QUADROS, Fausto de; MARTINS, Ana Maria Guerra. Contencioso Comunitário. Coimbra: Almedina. 2005.

QUADROS, Inês. A Função Subjetiva da Competência Prejudicial do TJ das Comunidades Europeias. Coimbra: Almedina, 2006. 
SIEKMANN, Robert C.R. Introduction to International and European Sports Law. Haia: Asser Press, 2012.

SIEKMANN, Robert; SOEK, Janwillem. Models of sport governance in the European Union: the relationship between state and sport authorities. The International Sports Law Journal, n. 3-4, p. 93-102, Jul./Oct. 2010. Disponível em: <https://go.gale.com/ps/i.do?id=GALE\%7CA352250454\&sid=googleScholar\&v=2.1\&it=r\&l inkaccess $=$ abs $\&$ issn $=15677559 \& \mathrm{p}=\mathrm{AONE} \& \mathrm{sw}=\mathrm{w} \&$ userGroupName $=$ anon $\% 7 \mathrm{Ee} 2 \mathrm{c} 28 \mathrm{fed}>$. Acesso em: 26 out. 2021.

UNIÃO EUROPEIA. Carta dos Direitos Fundamentais da União Europeia. Disponível em: $<$ https://eur-lex.europa.eu/legalcontent/PT/TXT/PDF/?uri=CELEX:12016P/TXT\&from=FR>. Acesso em: 26 out. 2021.

UNIÃO EUROPEIA. Estatuto do Tribunal de Justiça da União Europeia. Disponível em: $<$ https://curia.europa.eu/jcms/upload/docs/application/pdf/2016-08/tra-doc-pt-div-c-00002016-201606984-05_00.pdf>. Acesso em: 26 out. 2021.

UNIÃO EUROPEIA. Tratado de Lisboa, que altera o Tratado da União Europeia e o Tratado que institui a Comunidade Europeia. Disponível em: <https://eur-lex.europa.eu/legalcontent/PT/TXT/HTML/?uri=OJ:C:2007:306:FULL\&from=PT\#>. Acesso em: 26 out. 2021.

UNIÃO EUROPEIA. Tratado sobre o Funcionamento da União Europeia. Disponível em: <https://eur-lex.europa.eu/resource.html?uri=cellar:9e8d52e1-2c70-11e6-b497-

01aa75ed71a1.0019.01/DOC_3\&format=PDF>. Acesso em: 26 out. 2021.

UNIÃO EUROPEIA. Tribunal de Justiça. Acórdão. Acórdão de 11 de abril de 2000, Deliège, C-51/96 e C-191/97, ECLI:EU:C:2000:199. Disponível em: < https://eur-lex.europa.eu/legalcontent/HR/TXT/?uri=CELEX:61996CJ0051>. Acesso em: 26 out. 2021.

UNIÃO EUROPEIA. Tribunal de Justiça. Acórdão. Acórdão de 12 de dezembro de 1974, Walrave, Case 36/74, ECLI:EU:C:1974:140. Disponível em: <https://eur-lex.europa.eu/legalcontent/EN/ALL/?uri=CELEX\%3A61974CJ0036>. Acesso em: 26 out. 2021.

UNIÃO EUROPEIA. Tribunal de Justiça. Acórdão. Acórdão de 14 de julho de 1976, Donà, Case 13/76, ECLI:EU:C:1976:115. Disponível em: < https://curia.europa.eu/juris/showPdf.jsf?text=\&docid=89406\&pageIndex=0\&doclang=PT\& mode $=1$ st $\&$ dir $=\&$ occ $=$ first $\&$ part $=1 \&$ cid=25112558> . Acesso em: 26 out. 2021 .

UNIÃO EUROPEIA. Tribunal de Justiça. Acórdão. Acórdão de 18 de julho de 2006, MecaMedina e Majcen v. Commission, Case C-519/04, ECLI:EU:C:2006:492. Disponível em: < https://eur-lex.europa.eu/legal-

content/EN/TXT/?uri=CELEX\%3A62004CJ0519\&qid=1640127895882>.

UNIÃO EUROPEIA. Tribunal de Justiça. Acórdão. Sexta Secção. Acórdão de 13 de abril de 2000, Lehtonen, C-176/96, ECLI:EU:C:2000:201. Disponível em: <https://eurlex.europa.eu/legal-content/EN/TXT/?uri=ecli:ECLI:EU:C:2000:201>. Acesso em: 26 out. 2021. 
UNIÃO EUROPEIA. Tribunal de Justiça. Court of Justice of the European Union (CJEU). Disponível em: <https://europa.eu/european-union/about-eu/institutions-bodies/courtjustice_pt>. Acesso em: 12 abr. 2021.

UNIÃO EUROPEIA. Tribunal de Justiça. Ordonnance de la Cour. Neuvième Chambre. Ordonnance de 16 de julho de 2015, Striani v. UEFA e URBSFA, C-299/15, ECLI:EU:C:2015:519. Disponível em: $<$ https://curia.europa.eu/juris/document/document_print.jsf;jsessionid=9ea7d2dc30d59058948 bba904ac69f1bb0780651571e.e34KaxiLc3qMb40Rch0SaxuQbNv0?doclang=FR\&text=\&pag eIndex $=0 \&$ part $=1 \&$ mode $=$ DOC $\&$ docid $=166101 \&$ occ $=$ first $\&$ dir $=\& c i d=869346>$. Acesso em: 26 out. 2021.

UNIÃO EUROPEIA. Tribunal de Justiça. Pedido de decisão prejudicial apresentado pelo Tribunal Comercial n. 17 de Madri (Espanha), em 27 de maio de 2021. Processo C-333/21, com as partes do processo principal European Superleague Company, S.L. e UEFA e FIFA. Disponível em: <https://eur-lex.europa.eu/legalcontent/PT/TXT/?uri=CELEX:62021CN0333>. Acesso em: 26 de outubro de. 2021.

UNIÃO EUROPEIA. Tribunal de Justiça. Quarta Secção. Acórdão. Reenvio prejudicial Fiscalidade-Imposto sobre o valor acrescentado (IVA)-Diretiva 2006/112/CE-Conceito de “desporto". Processo C 90/16. 26 out. 2017. Disponível em: <https://eur-lex.europa.eu/legalcontent/PT/TXT/HTML/?uri=CELEX:62016CJ0090\&from=EN>. Acesso em: 12 abr. 2021.

\section{DADOS DA PUBLICAÇÃO}

Categoria: artigo submetido ao double-blind review.

Recebido em: 30/04/2021.

Aceito em: 25/11/2021. 